\title{
TRAFFIC STUDIES OF URBAN MID BLOCK SECTION: A CASE STUDY OF PRAGATINAGAR TO AKHBARNAGAR \& AKHBARNAGAR TO RANIP CROSS ROAD
}

\author{
Ashish Padshala ${ }^{1}$ \\ ${ }^{I}$ Student of Civil Department, Gandhinagar Institute of Technology, Ahmedabad, 38007
}

\begin{abstract}
Traffic has grown in recently years. As vehicular traffic began to increase, the congestion on the streets began to hamper the safe and efficient movement of traffic. More and more accidents were caused, and serious problems of parking and environmental pollution began to felt. Therefore its necessary to give attention towards transportation and study the need for better geometric design, capacity, signals, roadway marking, street lighting etc. In this parametric study, level of service(LOS) of different segment has been practically carried out for stretch path of Pragatinagar to Akhbarnagar \& Akhbarnagar to Ranip Cross Road between destination points facing heaviest traffic problems. Expected solution we get from outcome is lead to potential improvement of traffic in the form of either expansion of width of roads, construction of fly over or by-pass, improvement of signal design
\end{abstract}

\section{INTRODUCTION}

In the recent scenario traffic is the major consent for any developing nation. Ahmadabad has become a mega city. Population growth in these areas has been more rapid in recently, due to the saturation of population within the city area and the consequent large-scale housing development in the peripheral areas. Due to mixing of the regional and city traffic, this is most prominent on the eastern (Naroda- Narol Highway) and the western (Gandhinagar -Sarkhej Highway) bypasses, which have become part of the city as it has grown rapidly. To ease the traffic congestion on the inner radial roads, the'132 feet ring road' was constructed but over time, traffic volume on the same has increased beyond predictions. The western part of Ahmadabad has developed mainly as a residential area and the eastern part has industrial states. Because of this, there is heavy traffic flow from west to east in the mornings and vice-versa in the evening. This causes serious traffic congestion on street and frequent traffic jams on the city roads during peak hours, accident problem, parking problem besides air pollution. Therefore its necessary to give attention towards transportation. In this parametric study, level of service of different segment has been practically studied by mid-span survey of this 132 feet ring road on which we selected, destination points of Pragatinagar to Akhbarnagar (1.6 km) \& Akhbarnagar to Ranip Cross Road (1.5km).

\section{METHODOLOGY}

Mixture of manual and automatic traffic volume study method has been applied to do the parametric study of traffic capacity. The process consist of different vehicle of different categories and has been listed in the table. The analysis done during peak hours at morning and evening. Classified under $15 \mathrm{~min}$ each interval, the total vehicle of

\section{RESULTS AND DISCUSSION}

different category is being multiple by PCU, so as to define all the vehicle as one unit as in passenger car unit.After the multiplication the total no vehicle can be calculated and hence on the basis of data $(\mathrm{V} / \mathrm{C}$ ratio and $\mathrm{PHF}$ ) is being calculated and on the basis of this L.O.S can be determine for each way.

\section{SCOPE OF WORK}

The purpose traffic study is to determine the significant increase in the traffic capacity in the recent year. The mixed traffic comprising of number of modes having different physical characteristics and speed flow behaviour reflecting heterogeneity is main feature of Indian traffic playing on metropolitan road network. The studies help to determine the number, movements, and classifications of roadway vehicles at a given location. These data can help identify critical flow time periods, determine the influence of large vehicles or pedestrians on vehicular traffic flow. Helping in selection of pavement, shoulder, width of road. Financial viability of privately financed toll roads can be possible through it. Determine system work at present and quality offer to the road user. Determine whether a particular section handling traffic much above or below its capacity. Accident rate, maintenance of highway, design of signals, traffic regulatory can be possible through vehicle volume count. Lots of research work is carried and still going on to interrelate the wide variations in static and dynamic characteristic of mixed traffic with the passenger car equivalent using the different methodology and equivalency criteria. Most of the traffic engineers are adopting the static PCU specified by HCM or Indian Road Congress (IRC: 106-1990) in analysis of different traffic situations and establishing LOS. 


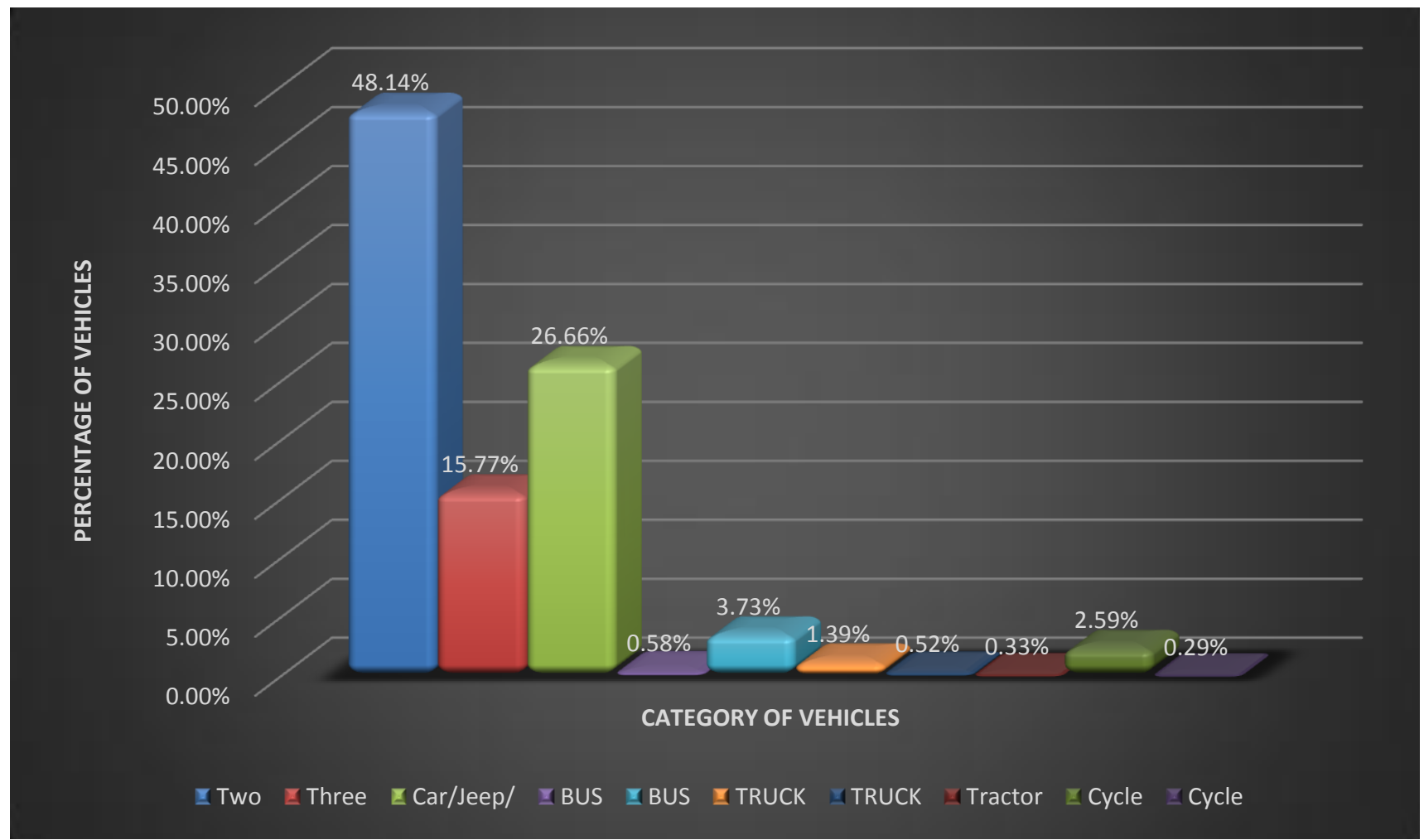

Flowchart of Pragatinagar to Akhbarnagar cross road

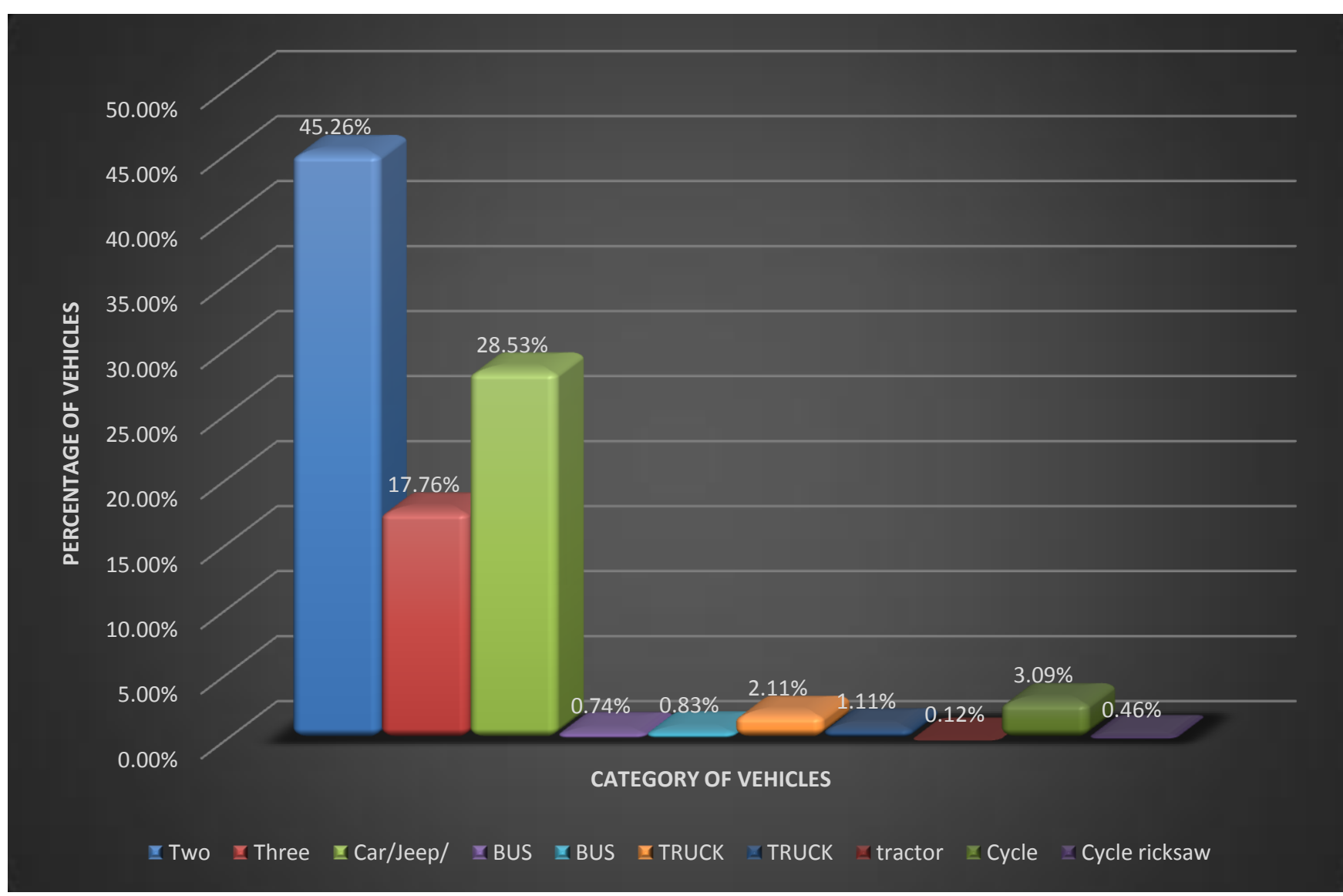

Flowchart of Akhbarnagar to Ranip cross road

Increases in the frequency of the vehicle on the stretch significantly descried in the above result in bar chart shows that on the basis of the manually acquired data various percentage of different categorized vehicles is obtained .On 
the basis of this we overcome on the result that situation is Forced flow, with jammed condition and the traffic flow is mixed traffic which carry more amount of traffic capacity above its exiting carrying capacity during peak hours, as this area comes under the highly commercial and residential area where movement traffic is continues.

\section{CONCLUSIONS}

From the overhead study we can determine that for v/c ratio as well as for peak hour factor the LOS is F for the stretch path of Pragatinagar to Akhbarnagar \& for the stretch Akhbarnagar to Ranip Cross Road the LOS of v/c ratio is B and for peak hour factor the LOS is F. The reason behind this capacity is increase in trips by personal mode of transportation by using two wheelers, three wheelers as well as personal cars. Some of the other reasons are decrease in width of road by BRTS(not completed its phase yet), improper management of traffic along the intersection, illegal parking along the carriage way, merging of traffic from different directions, lack of public awareness.

\section{FUTURE SCOPE}

This type of the parametric study can be carried out on the various segments for which Individual traffic carrying capacity of the present period can be obtained and hence heavy intersection facing various types of problem can be effectively resolved.

\section{REFERENCES}

[1]. Aggarwal Praveen (2008), "Passenger Car Unit Concept, Significance and affecting Factors", Indian Highways, Vol.36, pp. 23-31.

[2]. Dr. L.R.kadiyali ,'Traffic engineering and Transportation Engineering"' .

[3]. Tom V. Mathew and K V Krishna Rao,'Introduction to Transportation Engineering “.

[4]. Sharma, S. C. 1994. Seasonal Traffic Counts for a Precise Estimation of AADT.ITE Journal, Vol. 64, No. 9, pp. 34-41.

[5]. "Highway Capacity Manual" (2000) Special Rep. 209, Transportation Research Board, Washington, D.C. Indian Road Congress (1990) Guidelines for capacity of urban roads in plain areas, IRC: 106, New Delhi.

[6]. Marwah, B.R. and Singh, B. (2000) "Level of service classification for urban heterogeneous traffic: A case study of Kanpur Metropolis", Paper presented at the fourth international symposium on Highway Capacity, Hawaii, June-July 2000.

[7]. SantoshA.Jalihal and Dr. T. S. Reddy, "The Changing Traffic Composition; Its Impact And Implications", presented at National Seminar on "Road Transportation in India: Emerging Trends and Techniques (RORTRAN 2002)", IIT, Kharagpur (West Bengal), India. 